\title{
STREET ART SEBAGAI KOMUNIKASI POLITIK: SENI, PROTES, DAN MEMORI POLITIK
}

\author{
Gede Indra Pramana ${ }^{1)}$ \\ Azhar Irfansyah 2) \\ Fakultas Ilmu Sosial dan Ilmu Politik,Universitas Udayana ${ }^{1}$ \\ email: indraprama@unud.ac.id \\ Fakultas Ilmu Komunikasi, Universitas Bhayangkara Jakarta Raya ${ }^{2}$ \\ email:azhar.irfansyah@dsn.ubharajaya.ac.id
}

\begin{abstract}
ABSTRAK
Penelitian ini berusaha mengungkapkan fenomena seni jalanan. Dalam studi komunikasi politik, seni jalanan, dalam beragam bentuknya, sering kali diidentifikasi sebagai bentuk partisipasi politik nonformal. Pada praktiknya, seni jalanan menjadi lahan subur tumbuhnya aksi protes dan mengambil posisi kritis dalam isu politik, sosial, dan budaya. Dalam kanon keilmuan politik, bentuk partisipasi dominan dari warga negara umumnya dikaji dalam hubungannya dengan praktik elektoral. Kajian tentang partisipasi politik non-elektoral, yang berada diluar praktik representasi formal, minim dalam kajian ilmu politik. Dengan mengambil praktik mural yang dilakukan sekelompok anak muda di ruang publik, maka dapat digambarkan bentuk partisipasi politik non-elektoral, dan menangkap relasi antara politik dan seni. Fokus kajian ini adalah praktik partisipasi politik non-elektoral pada periode pasca Soeharto.Penelitian ini berupaya untuk membaca kembali praktik seni jalanan ini, secara khusus mural yang dikembangkan oleh Komunitas Pojok. Sejak 2002, Komunitas Pojok aktif berkarya di Kota Denpasar. Jarang sekali, untuk tidak mengatakan tidak ada, sebuah kolektif yang bertahan dan secara reguler menyelenggarakan perayaan terhadap seni jalanan. Karya mereka yang mengangkat isu sosial yang spesifik, seperti Hak Asasi Manusia, menjadi statemen politis atas keberpihakan mereka terhadap isu yang seringkali diabaikan oleh Negara.
\end{abstract}

Kata Kunci: Street Art, Non-formal Political Participation, Memory Politics

\section{ABSTRACT}

This research tries to reveal the phenomenon of street art. In the study of political communication, street art, in its various forms, is often identified as a form of informal political participation. In practice, street art becomes a fertile ground for protests and takes critical positions on political, social and cultural issues. In the political science canon, the dominant form of citizen participation is generally examined in relation to electoral practice. Studies on non-electoral political participation, which are outside the practice of formal representation, are minimal in the study of political science. By taking a mural practice that was carried out by a group of young people in public spaces, it can be described a form of nonelectoral political participation, and capturing the relationship between politics and art. The focus of this study is the practice of non-electoral political participation in the post-Soeharto period.This research seeks to re-read the practice of street art, specifically the murals developed by the Pojoks. Since 2002, the Pojoks has been actively working in the city of Denpasar. Rarely we find a collective survives and regularly organizes celebrations for street art. Their work that addresses specific social issues, such as Human Rights, becomes a political statement of their alignments to issues that are often ignored by the State.

Keywords: Street Art, Non-formal Political Participation, Memory Politics 


\section{PENDAHULUAN}

Penelitian ini berusaha mengungkapkan fenomena seni jalanan di Denpasar. Dalam studi komunikasi politik, seni jalanan dalam berbagai bentuknya sering kali diidentifikasi sebagai bentuk partisipasi politik non-formal. Pada praktiknya, seni jalanan menjadi lahan subur tumbuhnya aksi protes dan mengambil posisi kritis dalam isu politik, sosial, dan budaya.

Iklim politik suatu negara sering kali mempengaruhi dinamika perkembangan seni budayanya. Di Indonesia, ragam seni ini bertumbuh seiring menguatnya protes terhadap Orde Baru Soeharto. Setelah Soeharto mengundurkan diri, seni jalanan berkembang laiknya cendawan di musim hujan.

Dalam kanon keilmuan politik, bentuk partisipasi dominan dari warga negara umumnya dikaji dalam hubungannya dengan praktik elektoral. Kajian tentang partisipasi politik non-elektoral, yang berada di luar praktik representasi formal, minim dalam kajian ilmu politik. Dengan mengambil praktik mural yang dilakukan sekelompok anak muda di ruang publik, maka dapat digambarkan bentuk partisipasi politik non-elektoral, dan menangkap relasi antara politik dan seni. Fokus kajian ini adalah praktik partisipasi politik non-elektoral pada periode pasca Soeharto.

Salah satu praktik seni jalanan yang mengisi ruang publik adalah mural/grafiti. Perkembangan bentuk seni ini semakin signifikan, yang mana kehadirannya semakin mudah ditemui di kota-kota Indonesia. Karya-karya mural yang awalnya tumbuh di tembok-tembok kota, menjadi ikon protes terhadap situasi sosial dan politik di Indonesia. Salah satunya adalah sketsa wajah Munir, sosok pembela Hak Asasi Manusia yang meninggal diracun di udara, karya seniman Antitank (Yogyakarta) yang menjadi begitu ikonik sebagai simbol perlawanan masyarakat sipil di Indonesia.

Jakarta, Bandung, Yogyakarta, dan Denpasar muncul seniman-seniman yang menggoreskan kuasnya, menggambar tembok di sudut kota guna menyuarakan kritik terhadap isu dan situasi sosial. Nama-nama besar seperti Taring Padi (Yogyakarta), Taring Babi (Jakarta) atau Apotik Komik (Yogyakarta) adalah kolektif artis yang besar dalam situasi represi Orde Baru. karya-karya yang mereka secara lugas menyerang Rezim Orde Baru. Perubahan politik yang terjadi setelah tumbangnya Orde Baru membawa nuansa baru dalam kekaryaan seniman jalanan hari ini. Karya mereka relatif membawa topik-topik yang lebih luas, seperti isu lingkungan, tapi juga isu pelanggaran hak asasi manusia.

Penelitian ini berupaya untuk membaca kembali praktik seni jalanan ini, secara khusus mural yang dikembangkan oleh Komunitas Pojok. Sejak 2002, Komunitas Pojok aktif berkarya di Kota Denpasar. Salah satunya adalah Bali yang Binal, sebuah inisiatif bienale seni jalanan, yang mereka gagas sejak tahun 2005 hingga sekarang. Jarang sekali, untuk tidak mengatakan tidak ada, sebuah kolektif yang bertahan dan secara reguler menyelenggarakan perayaan terhadap seni jalanan.

Jejak mural dalam sejarah panjang perjalanan Republik, dapat kita lacak kehadirannya melalui coretan besar di gerbong kereta pada periode revolusi 1945 1949, "Merdeka Ataoe Mati," yang tertulis besar-besar sebagai peringatan kedatangan 
kembali tentara NICA yang mengancam kemerdekaan Indonesia. Dengan jelas, praktik itu berinti pesan propaganda yang bermakna ganda. Ia berarti ajakan perjuangan kepada seluruh elemen pendukung revolusi, sekaligus peringatan bagi mereka yang diidentifikasi sebagai musuh besar revolusi.

Praktik ini kemudian dimaknai secara peyoratif, sejalan dengan formasi Orde Baru paska peristiwa 1965. Kebudayaan, yang dimaknai secara umum sebagai hasil cipta, rasa, dan karsa, dihargai semata-mata berdasarkan rasa penciptaan, tanpa kesadaran sosial yang melingkupi, dan pesan yang terkandung di dalamnya. Kebudayaan adalah tradisi adiluhung yang diwariskan secara turun temurun. Dengan kata lain, kesenian harus steril, jauh dari pesan politik, baik berupa protes maupun kritik sosial.

Kajian tentang seni jalanan mulai mendapatkan perhatian lebih oleh ilmuwan politik, pada saat yang hampir berbarengan dengan meningkatnya penggunaan media sosial. Hal ini menandakan karya seni, seperti Banksy misalnya, memiliki suatu aspek politis, yang darinya dapat kita lihat suatu komentar, bahkan kritik, terhadap situasi sosial yang berlangsung di berbagai belahan dunia. Hal ini bukan berarti karya seniman lain tidak memiliki dampaknya. Beragamnya bentuk, medium, gaya, genre, dan ekspresi visual dari seni jalanan ini adalah faktor-faktor yang mempengaruhi tingkat kesulitan dalam merefleksikan secara proporsional cakupan dan pengaruh yang dihasilkan oleh karya-karya seniman di seluruh dunia (Ferrel, 2016).

Seni jalanan dapat dimaknai sebagai, "Also commonly referred to as "urban art" or "guerilla art," street art may be categorized under the broader term of "public art," as described by Peter Bengtsen (2013) in A Critical Examination of Street Art as Public Art. Although Bengtsen struggles to make a clear separation between street art and public art, he emphasizes that, "the unsanctioned nature of street art serves as an essential carrier of meaning” (Bengtsen, 2013, p. 78). Street art's illicit nature is an embodiment of its rebellious and dynamic qualities as a form of art that is uncensored and open to the public. This "unsanctioned nature," leads right into the complexities surrounding street art, and the very beginnings of the word vandalism, that is most commonly bound to our perception of street art and graffiti."

Pada perkembangannya, seni jalanan acapkali dikaitkan dengan vandal. Vandal, sebuah kata yang mulai dipergunakan pada abad ke-18 pada periode Revolusi Prancis, saat seorang Pendeta Prancis menyatakan Vandalisme guna menggambarkan kerusakan dan penghancuran oleh orang-orang Germanic yang disebut Vandals. Hari ini vandalisme, "became the standard term, not only for systematic revolutionary violence, but for any act of cultural desecration, particularly against art and architecture" (Merrills, 2009, p. 156).

Meski demikian, hal ini bukan berarti kesulitan-kesulitan dalam menilai status dan makna karya seniman jalanan ini menghalangi upaya guna melihat fenomena ini secara lebih jernih. Paling tidak, fenomena urban seni jalan ini dipengaruhi oleh dua trajektori, yaitu: pertama, melibatkan pertumbuhan yang stabil dari pengawasan kota dan rezim kepolisian, strategi manajemen risiko, dan desain lingkungan yang terbatas. Daerah perkotaan di AS, Eropa dan sekitarnya saat ini dibanjiri kamera 
pengintai/CCTV, alat pelacak sonik, dan sensor gerak - dan semakin meningkat. Kedua, menunjukkan ekonomi politik baru kehidupan perkotaan - ekonomi politik yang oleh para ahli teori ekonomi disebut 'pembangunan perkotaan yang didorong oleh konsumsi (Markusen dan Schrock 2009).

\section{METODE PENELITIAN}

Penelitian ini menggunakan studi kasus. Metode studi kasus memungkinkan dilakukan penyelidikan secara tajam dalam memahami seni jalanan, melalui pengalaman para senimannya. Studi kasus menekankan pemahaman mendalam terhadap subjek kajian, pengalaman spesifik dari subjek-, konteks yang melingkupi fenomena dalam kasus, dan pemahaman yang muncul dari kasus yang berlangsung.

Langkah-langkah yang ditempuh di dalam penelitian ini antara lain:

a. Studi literatur dilakukan dengan pendekatan komunikasi politik, guna memperoleh pemahaman tentang: 1) posisi subjek seniman jalanan dalam publik, relasinya terhadap karya, dan kota sebagai ruang berkarya; 2) karya seni sebagai mode kritik terhadap kuasa dominan; 3) praktik kesenian sebagai bentuk protes, dan partisipasi politik non-formal; 4) konteks politik umum yang melingkupi seniman jalanan dalam komunikasi politik. Penelitian lapangan secara umum bertujuan untuk mendapatkan data mendetail mengenai seni jalanan yang dilakukan oleh Komunitas Pojok, yang melibatkan seniman-seniman anggota komunitasnya. Data yang dikumpulkan berfokus pada motif dan dinamika aktor. Pemetaan aktor dilakukan kepada aktor-aktor yang terlibat, atau mitra sosial, yang terlibat dalam proses-proses penciptaan karya. Pemetaan juga melihat kelindan kepentingan dari masing-masing aktor dalam berkarya, persepsinya terhadap mitra lainnya dan juga persepsinya terhadap apa itu seni jalanan, serta posisi tawar yang mereka gunakan di dalam proses berkarya. Secara keseluruhan, proses inilah yang menentukan posisi mereka dengan karya dan kota.

b. Tahapan selanjutnya menggali hal-hal yang meliputi di sekitar seni jalanan dan proses berkarya: 1) Tahap persiapan, yaitu periode awal dari pekerja dalam menentukan tema yang akan digunakan dalam karya seni mereka. Secara khusus akan diurai proses persiapan dan perencanaan, dan proses eksekusi karya; 2) Praktik, yang mencakup bentuk-bentuk dialog, isu-isu dan tema yang diangkat dalam karya mereka; 3) Tahap akhir ini berupaya melihat hasil dari proses berkarya seniman, dampaknya terhadap organisasi ruang publik, dan respons terhadap karyanya. Selain itu, bagian ini berupaya membongkar praktik berkesenian, dan menempatkan seni jalanan dalam konteks politik yang lebih luas; 4) Wawancara semi terstruktur dan wawancara mendalam akan dilakukan kepada anggota Komunitas Pojok; 5) Observasi partisipatif kepada anggota Komunitas Pojok; 6) Wawancara semi terstruktur akan dilakukan kepada anggota Komunitas Pojok.

\section{HASIL DAN PEMBAHASAN}

Bagian ini dibagi menjadi dua bagian. Bagian pertama akan mengulas praktik mural dalam lintasan sejarah, untuk kemudian mengontekskannya dalam periode 
penelitian ini. Bagian kedua akan secara spesifik mengulas karya kolektif dari Komunitas Pojok, Mata Rantai yang Hilang (The Missing Link). Karya ini dikaji, selain karena aspek kebaruan dari karyanya, juga karena resonansi problem nasional yang muncul dalam karya ini. Hal ini menjadi menarik karena praktik kesenian di Bali umumnya berkutat dalam budaya pariwisata, suatu hal yang didobrak dalam karya Mata Rantai yang Hilang.

Kekayaan seni dan budaya masyarakat Bali telah lama masyhur dalam imaji surga terakhir. Imaji ideal ini terus dijaga dan direproduksi, sejalan dengan kepentingan negara dan kapital. Pariwisata adalah panglima. Padahal, di balik gemerlap pariwisata Bali ada sejarah kekerasan yang menjadi prakondisi perubahan lanskap ekonomi dan politik budaya secara masif (Farid, 2005). Tak keliru kiranya jika dinyatakan bahwa ledakan pariwisata Bali dibangun dari puing-puing yang tersisa pasca-peristiwa 1965.

Kuatnya arus modal dan besarnya kapital yang berputar mendorong perubahan dalam hubungan budaya masyarakat Bali. Ledakan pariwisata membuat masyarakat Bali tersadar bahwa alam, seni ,dan budayanya adalah modal penting dalam menggaet kunjungan jutaan wisatawan tiap tahunnya. Imaji Bali yang damai harus dipertahankan sedemikian rupa sehingga tidak mengganggu laju modal pariwisata (Santikarma, 2003).

Seiring perkembangan industri pariwisata, diperlukan suatu bangunan kesenian budaya guna menopang keberlangsungannya. Bentuk-bentuk kesenian pun tak lepas dari pengaruh ini. Berbagai festival seni, pameran, dan institusi pendukungnya didorong guna melayani derasnya permintaan pasar. Kesenian publik juga tak lepas dari komodifikasi ini. Padahal dalam rentang sejarahnya, seni dan budaya Bali tak dapat dilepaskan dari konteks lokal yang orientasinya bukan semata-mata pasar, melainkan juga perayaan ritual keseharian, beserta komitmen sosial yang menyertainya (Geertz, 1991).

Di Indonesia, kemunculan mural dapat ditemukan paling tidak sejak periode revolusi. Pada dinding-dinding kota wilayah Republik Indonesia yang sedang bergejolak, tulisan-tulisan di gerbong kereta berisi seruan upaya propaganda mendukung kemerdekaan. Secara mencolok, gambaran ini menutupi dinding-dinding kota yang porak-poranda akibat perang yang berkecamuk selama aksi polisionil Belanda.

Ketertarikan kembali atas mural tidak dapat dilepaskan dari konteks runtuhnya Orde Baru, yang berkuasa di Indonesia selama lebih kurang 32 tahun. Sejak runtuhnya Orde Baru, yang menandai suatu periode keterbukaan politik, muncul berbagai individu dan kelompok, yang merespons era keterbukaan tersebut melalui karya-karya seni. Kelompok ini berhubungan erat dengan aktor-aktor yang sebelumnya berperan dalam gerakan melawan rezim Orde Baru.

Di kota-kota besar seperti Jakarta atau Yogyakarta misalnya, muncul kelompokkelompok seniman yang berupaya untuk membawa seni ke khalayak publik yang luas dan secara sadar memilih berkarya di ruang publik. Secara khusus di sini perlu disebutkan, Lembaga Kebudayaan Kerakyatan Taring Padi, dan Apotik Komik, dua kolektif seniman yang ada di Yogyakarta. Keduanya berperan aktif, dengan cara yang 
berbeda, dalam mengembangkan metode guna menjangkau publik dengan karya-karya seni mereka.

Pada 1999, Taring Padi dan Apotik Komik menyelenggarakan pameran seni rupa publik. Pameran bertajuk "Sakit Berlanjut" ini diselenggarakan di Malioboro, Yogyakarta. Karya Taring Padi menegaskan aspek kolektivitas dalam kekaryaan, dengan pesan yang gamblang dan cenderung provokatif. Dalam poster yang dipasang tepat di depan kantor Dewan Perwakilan Rakyat Daerah Provinsi Yogyakarta, menggambarkan sekerumunan babi yang mengenakan topi baja dan sepatu lars militer, dikerangkeng dalam sebuah usungan. Beberapa figur manusia bercaping, berkopiah, dan ada pula yang mengenakan baju kaus bertulisan "Persatuan Buruh Becak". Di tengah kerumunan itu, muncul sosok berpakaian hitam dengan balon teks berbunyi, "Koalisi rakyat sipil demokratis. Hapuskan 38 kursi gratis di MPR DPR". Teks lain semakin memperkuat unsur propaganda dari teks ini: "Demokrasi sejati adalah tanpa militer."

Kelompok Apotik Komik berekspresi dengan menggunakan gaya visualisasi komik yang tidak konvensional. Mereka membentuk figur-figur manusia yang sudah dipiuhkan (dideformasi) dari bahan karton yang digambari dengan tinta cina, sehingga menghasilkan figur yang terkesan aneh.

Taring Padi dikenal luas sebagai kolektif seni yang menggunakan karyakaryanya sebagai bentuk kritik sosial. Individu-individu dalam Apotik Komik kemudian lebih lanjut membawa mural di tembok-tembok kota Yogyakarta. Peristiwaperistiwa ini boleh jadi menandai napas seni publik yang muncul pada dekade-dekade berikutnya.

Di Bali, salah satu komunitas seniman yang konsisten melakukan festival seni publik, dalam pengertiannya yang paling luas, adalah Komunitas Pojok. Sejak aksi "Mendobrak Hegemoni", sebuah gugatan terhadap aras seni rupa dominan Bali kala itu, yang diinisiasi oleh Keluarga Mahasiswa Seni Rupa Sekolah Tinggi Seni Indonesia (Kamasra STSI) ini menggemakan perlawanan terhadap tendensi karya-karya seni rupa yang mendominasi seni rupa Bali kala itu.

Berawal dari aksi Mendobrak Hegemoni di tahun dua ribu awal. Kami sebagai seniman muda sangat frontal menggugat hegemoni seniman-seniman tua. Pada waktu itu seniman tua diwakili oleh Sanggar Dewata. Seniman tua itu geng-gengnya Gunarsa, Erawan dsb. Karya kami waktu aksi itu kasar banget. Total mengejek mereka lewat karya pelesetan. Sanggar Dewata kami rubah jadi Sangkar Dewata. Kami sebut mereka Sangkar Dewata karena dari yang tua hingga yang muda karyanya monoton itu-itu saja. Mereka seperti terkurung dalam sangkar.

Waktu itu belum ada komunitas Pojok. Aksi itu digelar oleh Kamasra (Keluarga mahasiswa seni rupa). Pada saat itu orang-orang Komunitas Pojok bernaung di Kamasra. Orang-orang itu terkenal paling nakal di Kamasra. Dari semenjak aksi Mendobrak Hegemoni itulah kami diawasi kampus.

Setelah itu Kamasra membuat aksi Kontra PKB (Pesta Kesenian Bali) yang kami pelesetkan menjadi Pesta Kapitalis Bali, atau Pemerintah Kolonial Bali. Karena aksiaksi itu Kamasra diamati ketat. Teman-teman akhirnya menyempal membentuk 
komunitas-komunitas, salah satunya Komunitas Pojok.

Sedari awal, Komunitas Pojok hadir sebagai kritik. Seni dan kritik menjadi praktik yang diamini, berlawanan dengan praktik seni yang dominan di Bali. Praktik seni sebagai kritik ini menjadi spirit, hadir dalam beragam bentuk karya seni yang, dengan kadar yang berbeda-beda, mengeksplorasi kemungkinan-kemungkinan.

Pada tahun 2002, untuk pertama kalinya, Komunitas Pojok menggelar pameran berjudul "Tentang Manusia". Pada 2004, Komunitas Pojok berkesempatan untuk pameran di Kedai Kebun Forum, Yogyakarta, bertajuk "Under Attack". Inilah pameran pertama Komunitas Pojok di luar Bali. Interaksi yang cukup intens selama di Yogyakarta, utamanya dengan Samuel Indratma, berujung pada karya mural kolaborasi berjudul "Under Garbage" di Jalan Katamso, Yogyakarta.

Sepulang dari Yogyakarta, tak butuh waktu lama bagi Komunitas Pojok untuk kembali melukis mural di tembok kota Denpasar, tepatnya di Jalan Akasia, atas tawaran Diego, Ari Diyanto, dan Klinik Seni Taxu. Di penghujung tahun yang sama, Komunitas Pojok diundang untuk berpartisipasi dalam Street Art Festival yang diselenggarakan di Jakarta.

Sejak 2005, Komunitas Pojok menginisiasi sebuah festival seni dua tahunan di Denpasar, Bali yang Binal. Bali yang Binal (disingkat BYB) adalah sebuah festival seni yang lahir dari sebuah kritik pada Bali Biennale 2005. BYB diinisiasi para seniman muda yang waktu itu tergabung dalam Komunitas Pojok dan Komunitas Seni di Denpasar (KSDD). Nama Bali yang Binal sendiri adalah parodi dari Bali Biennale. Ketika Bali Biennale mati di tahun pertamanya, BYB justru mampu berjalan hingga ke edisi \#7 pada 2017 lalu. Sebagai sebuah festival dua tahunan yang terlahir dari kritik, BYB selalu membawa tema spesifik yang terbungkus dengan baik secara estetik.

Komunitas Pojok menyelenggarakan Bali yang Binal ketujuh bertajuk "Relief Sungai”. Perhelatan festival ini berlangsung selama satu bulan penuh, membuka ruang partisipasi sebesar-besarnya bagi publik umum maupun seniman untuk terlibat. Kebebasan diberikan seluas-luasnya, melalui ragam bentuk dan medium masingmasing. Lokasi-lokasi mural yang dipilih para artis pun beragam: tembok jembatan, rumah tua tak berpenghuni, hingga tembok di sepanjang pinggiran sungai.

Di malam penghujung Bali yang Binal ketujuh, diselenggarakan konser dan pameran di Taman Pancing Pemogan, salah satu muara sungai besar di kota Denpasar. Sepanjang malam pertunjukan ramai oleh musisi-musisi yang bergantian mengisi panggung. Tembok di sekitar Taman Pancing telah penuh oleh mural-mural karya Wild Drawing, Slinat, Peanut Dog, 735art dan banyak seniman lain yang meramaikan Bali yang Binal. Para pengunjung yang bergerombol di kedua sisi sungai, berbaur dengan warga sekitar. Keriuhan malam itu seolah pasar malam, suatu tradisi yang lazim dalam kehidupan warga kota.

Komunitas Pojok sendiri memasuki umur yang ketujuh belas pada 2018, bukti lain dari nafas panjang komunitas seni ini. Sejak awal kemunculannya, Komunitas Pojok menawarkan alternatif terhadap seni tradisi yang telah mendarah daging dalam sirkuit seni Bali. Hal ini bukan berarti penolakan total terhadap apa-apa yang berbau tradisi. Bagi mereka, berkesenian harus memiliki pesan (sosial), baru kemudian 
estetika. Secara lebih spesifik, mereka menekankan proses penggalian isu di masyarakat, kemudian mengangkat isu-isu yang jarang mendapat perhatian, serta menyuarakannya melalui praktik seni.

Menurut Komunitas Pojok, pilihan medium, bentuk, dan ruang pameran yang hadir selama ini berputar dalam orbit yang itu-itu saja. Komunitas Pojok memilih keluar dari kampus seni, rahim institusi yang melahirkannya, keluar dari galeri yang nyaman berpendingin udara, yang hanya bisa dinikmati oleh kalangan itu-itu saja. Banyak karya mereka merespon perubahan lanskap kota Denpasar yang semakin urban. Jika ada kredo bagi Komunitas Pojok, mungkin kira-kira berbunyi: kota adalah galeri, tembok adalah kanvas, dan publik adalah pelaku sekaligus penikmatnya.

Pada tahun 2018, Komunitas Pojok memasuki umur yang ketujuh belas. Mural "The Missing Link", mungkin diniatkan sebagai semacam perayaan kecil, mungkin juga refleksi, atas proses berkesenian yang tidak bisa dikatakan singkat. Kehadiran mural itu tampak begitu mencolok. Perlahan-lahan, gambaran wajah itu semakin jelas menunjukan rupa wajah. Sosok wajah itu hadir tanpa nama. Pada salah satu tembok tertulis: "The Missing Link, Tujuh Belas Tahun Komunitas Pojok". Ada kutipan Pramoedya Ananta Toer di sana: "Kau Tak Kenal Bangsamu Sendiri."

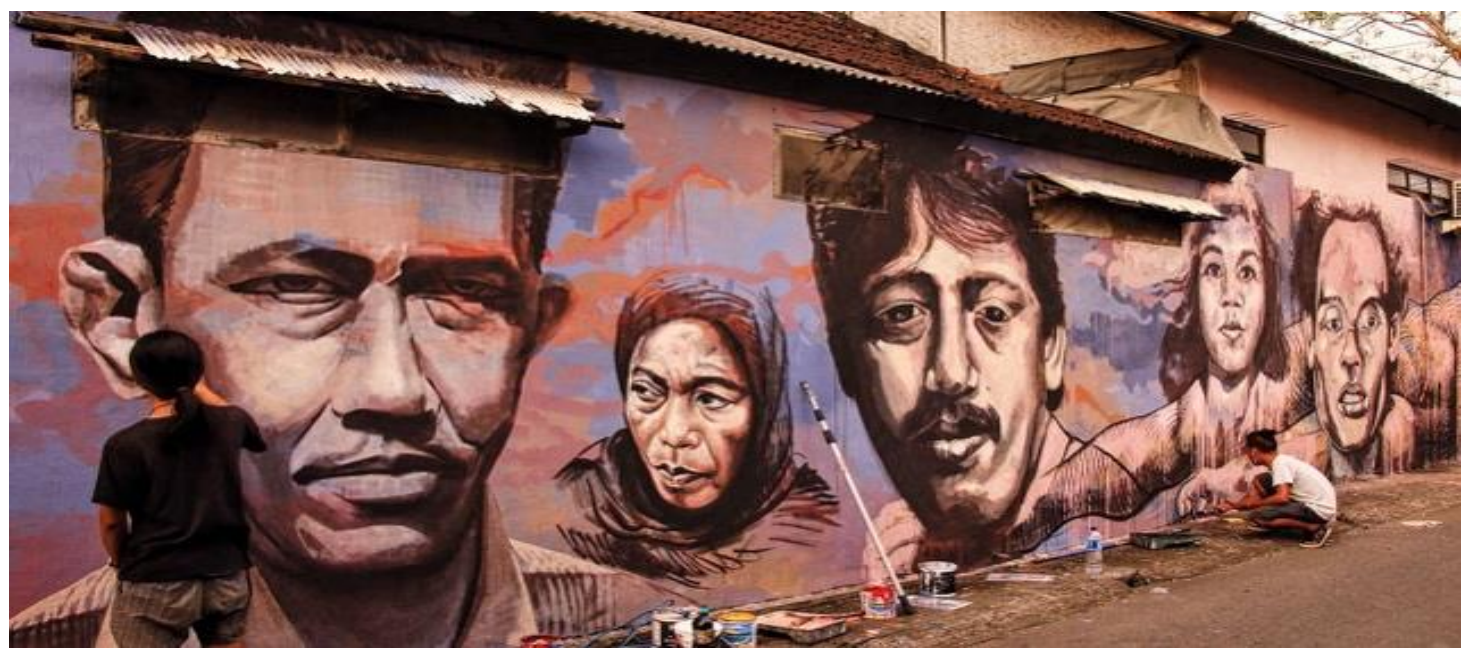

Mural The Missing Link. Foto dokumentasi Hadi Kusuma, 2018 dicantumkan dengan seizin pemilik

Apa pentingnya sosok wajah ditembok jalan tersebut? Jika diperhatikan, hampir semua sosok tersebut adalah sosok kritis terhadap rezim penguasa dalam berbagai periode sejarah Indonesia. Ada Wiji Thukul, sosok penyair yang dihilangkan ketika gelombang reformasi 1998 menerpa rezim Orde Baru, Soeharto dan melengserkannya. Ada Marsinah, seorang buruh perempuan yang ditemukan meninggal setelah ditahan aparat karena melakukan protes pada periode 1990; Munir Said Thalib, pengacara Lembaga Bantuan Hukum, pembela Hak Asasi Manusia, yang dibunuh oleh suatu 
operasi terorganisir dalam perjalanan guna melanjutkan studinya ke Belanda; Yu Padmi, petani Kendeng yang memprotes perampasan tanah kelahirannya, yang meninggal di depan Istana Negara; Datuk Ibrahim Tan Malaka, Bapak Republik Indonesia; Siluet wajah K.H. Abdurachman Wahid, presiden Republik Indonesia ketiga; Rupa Wajah Bergaris Merah, berpakaian destar putih memakai udeng; Bentuk ragam elaborasi mata; Bagi saya, mural itu berisi pesan yang gamblang. Kamilah momok bagi penguasa yang lalim. Mural itu sekaligus menyentak publik yang melihatnya dengan pertanyaan besar, "Kalian kenal kami?"

Mural ini menggambarkan komentar Komunitas Pojok terhadap situasi sosial hari ini akan problem masa lalu, dalam sejarah Indonesia, yang hingga kini masih belum tuntas. Representasi atas berbagai problem ini termaktub melalui sosok wajah yang hadir melalui mural.

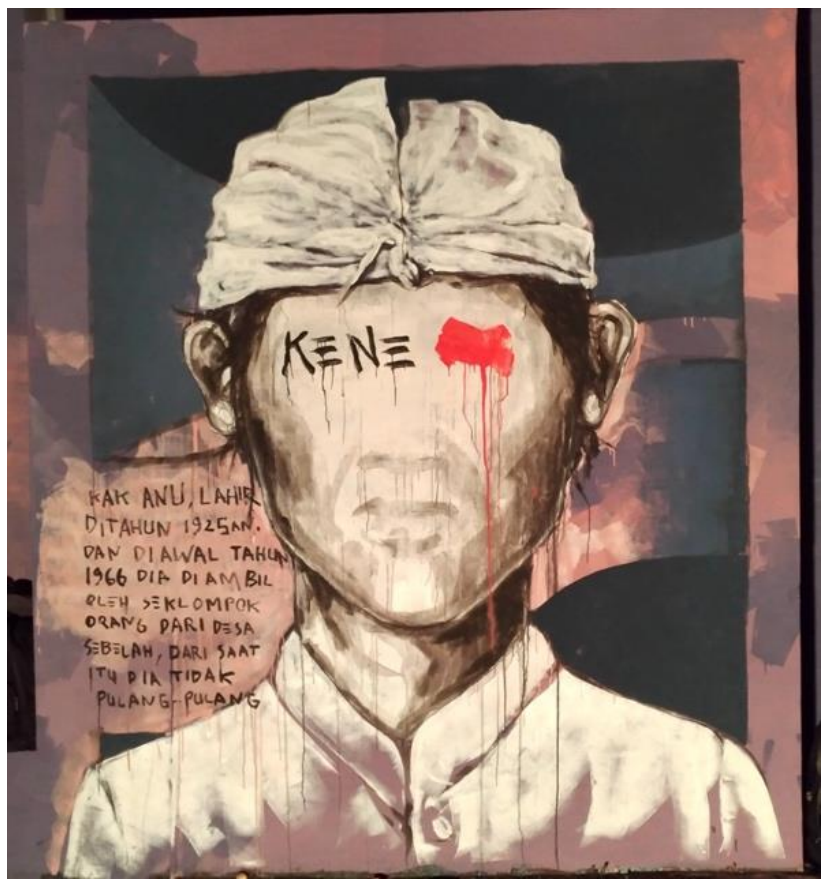

Pada salah satu mural karya Slinat, tertulis: "Kak Anu, lahir di tahun 1925an, dan di awal tahun 1966 dia diambil oleh sekelompok orang dari desa sebelah. Dari saat itu dia tidak pulang-pulang." Narasi ini begitu mengusik. Tak disebutkan sama sekali perihal peristiwa 1965, yang justru menjadi latar dari narasi tersebut. Publik menjadi bebas menikmati mural, tanpa perlu terbebani narasi peristiwa 1965, sekaligus diajak untuk berpikir mengenai peristiwa itu.

Jika dilihat secara keseluruhan, strategi naratif yang hadir dalam mural ini menghadirkan sebuah paradoks.

Sosok-sosok wajah familier, yang berperan penting dalam perjalanan sejarah Republik Indonesia, akan tetapi hadir tanpa nama. Mural dua buah tangan besar yang menerobos masuk, mengontrol otak dalam sangkar, di satu sisi, sekaligus sosok tubuh yang berbaring kesakitan menutup telinga, meresonansi situasi sejarah yang digelapkan, sekaligus praktik pembodohan yang menyertainya pada masyarakat kita hingga kini.

"Mural hadir untuk merebut kembali ruang publik, yang selama ini dirampas oleh iklan-iklan milik perusahaan besar. Mengembalikan publik pada ruang publik, dengan kata lain, menjadi semangat yang mendasari seni jalanan. (Komunitas Pojok)"

Pernyataan ini membuka diskusi 17 tahun Komunitas Pojok yang diselenggarakan pada Minggu, 25 Februari 2018 yang lalu. Sore itu puluhan orang hadir memadati beranda Taman Baca Kesiman, Denpasar. Sebagai rangkaian perayaan bulan Pram, agenda rutin tahunan Taman Baca Kesiman, kali ini menggandeng 
Komunitas Pojok dalam diskusi "Mata Rantai yang Hilang."

Dalam diskusi tersebut ada kesepakatan menarik, suatu aturan main, yang mana para peserta diharapkan tidak mengambil dokumentasi wajah para narasumber yang hadir. Suatu praktik lazim bagi seniman jalanan. Sebanyak lima orang perwakilan Komunitas Pojok hadir ketika itu. Para peserta tampak larut, hanyut dalam obrolan hingga tak terasa waktu telah beranjak hingga jauh malam.

\section{KESIMPULAN}

Apabila keberlangsungan komunitas tidak dapat dilepaskan dari ruang sosial tempatnya hidup, tentu lingkungan sosial mempengaruhi keberadaan komunitas. Bagi Komunitas Pojok, isu sosial/politik tampaknya menjadi pilihan bagi praktik berkesenian mereka. Dengan mempertahankan idealisme, [yang] adalah kemewahan terakhir yang dimiliki pemuda, Komunitas Pojok menegaskan kembali arti penting seni publik di Denpasar.

\section{DAFTAR PUSTAKA}

Andan, M. (2011). All for Jakarta - a note on the tenth anniversary of ruangrupa: Decompression \#10, Expanding the Space and Public. Inter-Asia Cultural Studies, 12(4), 591-602.

Banksy, \& Bull, M. (Eds.). (2015). This is not a photo opportunity: The street art of Banksy. Oakland, Calif: PM Press.

Banksy. (2007). Wall and Piece UK: Random House Publishing

Barthes, Roland, Empire of Signs, New York: Hill and Wang, The Noon Day Press, 1982 (Translated by Richard Howard)

Bengtsen, P. (2013). Beyond the Public Art Machine: A Critical Examination of Street Art as Public Art. Konsthistorisk Tidskrift/Journal of Art History, 82(2), 63-80.

Cartiere, C., \& Willis, S. (Eds.). (2008). The Practice of Public Art. New York: Routledge.

Chu, L. (2016). Talking Walls: Freeing Art in Bali, Indonesia. 61. Independent Study Project (ISP) Collection. 2590.

Fadjri, R. Antara Seni Rupa Individual dan Komunal, Tempo, 25 Juli 1999. Diakses dari http://archive.ivaaonline.org/files/uploads/texts/Antara\%20Seni\%20Rupa.pdf

Farid, Hilmar (2005) Indonesia's Original Sin: Mass Killings and Capitalist Expansion, 1965-66, Inter-Asia Cultural Studies, 6:1, 3-16

Gardiner, M., Nadarajan, G., \& Soussloff, C. (2012). The Handbook of Visual Culture (I. Heywood \& B. Sandywell, Eds.).

Geertz, Hildred. (1991) A Theater of Cruelty: The Context of Topeng Performance, dalam State and Society in Bali, Leiden: KITLV Press, 165-197

Lee, D. (2011). Styling the Revolution: Masculinities, Youth, and Street Politics in Jakarta, Indonesia. Journal of Urban History, 37(6), 933-951.

Lee, D. (2013). "Anybody Can Do It": Aesthetic Empowerment, Urban Citizenship, and the Naturalization of Indonesian Graffiti and Street Art: "Anybody Can Do 
It." City \& Society, 25(3), 304-327.

Lee, D. (2015). A Troubled Vernacular: Legibility and Presence in Indonesian Activist Art. The Journal of Asian Studies, 74(2), 303-322.

MacDowall, L. J., \& de Souza, P. (2018). 'I'd Double Tap That!!': Street art, graffiti, and Instagram research. Media, Culture \& Society, 40(1), 3-22.

Merrills, A. H. (2009). The Origins of 'Vandalism.' International Journal of the Classical Tradition, 16(2). 155-175

Putra, Gde, Dari Bali yang Binal, Ruang Publik, dan Komunitas Pojok, https://pekrimikbali.wordpress.com/2013/05/14/dari-bali-yang-binal-ruangpublik-dan-komunitas-pojok/

Riggle, N. A. (2010). Street Art: The Transfiguration of the Commonplaces. The Journal of Aesthetics and Art Criticism, 68(3), 243-257.

Roitman, S. (2019). Urban Activism in Yogyakarta, Indonesia: Deprived and Discontented Citizens Demanding a More Just City. In N. M. Yip, M. A. Martínez López, \& X. Sun (Eds.), Contested Cities and Urban Activism (pp. 147-174).

Barthes, Roland. (1983). Empire of Signs, Hill and Wang

Ross, J. I. (Ed.). (2016). Routledge handbook of graffiti and street art. London; New York, NY: Routledge.

Ross, J. I., Bengtsen, P., Lennon, J. F., Phillips, S., \& Wilson, J. Z. (2017). In Search Of Academic Legitimacy: The Current State Of Scholarship On Graffiti And Street Art. The Social Science Journal, 54(4), 411-419.

Santikarma, Degung. (2003), Monumen, Dokumen, dan Kekerasan Massal, Politik Representasi Kekerasan di Bali, Kompas, Jumat, 01 Agustus 2003

Schacter, R. (2008). An Ethnography of Iconoclash: An Investigation into the Production, Consumption and Destruction of Street-art in London. Journal of Material Culture, 13(1), 35-61.

Slamet, I. (1974). Letter from Indonesia. Index on Censorship, 3(1), 60-64.

Tsilimpounidi, M., \& Walsh, A. (2011). Painting human rights: Mapping street art in Athens. Journal of Arts and Communities, 2(2), 111-122.

Trifonas, Peter Pericles, Barthes and The Empire of Signs, UK \& US: Icon Book \& Totem Books, 2001

Tsui, D. (2015). A Grassroots Perspective On Yogyakarta's Art World. Journal of Southeast Asian Studies, 46(3), 537-545.

Warcd, (tt) Just like Punk, the Pojoks not Dead, https://warcd.wordpress.com/2013/04/10/just-like-punk-the-pojoks-not-dead/

Young, A. (2014a). Cities in the City: Street Art, Enchantment, and the Urban Commons. Law \& Literature, 26(2), 145-161.

Young, A. (2014b). Street art, public city: Law, crime and the urban imagination. Abingdon, Oxon ; New York, NY: Routledge, Taylor \& Francis Group

Zaimakis, Y. (2016). Youth precariat worlds and protest graffiti in the dystopia of the Greek economic crisis: A cross-disciplinary perspective. Punctum. International Journal of Semiotics, 2(2), 